\title{
Global threats and the domestic struggle for power
}

\author{
Michelle R. Garfinkel* \\ Department of Economics, University of California-Irvine, Irvine, CA 92697-5100, USA
}

Received 10 March 2003; received in revised form 16 May 2003; accepted 15 June 2003

Available online 28 March 2004

\begin{abstract}
This paper considers an economy where groups compete in a contest for power to redistribute future income in their favor. An increased external threat of terrorism-either an increase in the likelihood of a successful terrorist attack or a greater loss of income in the event of a successful attack - would tend to reduce the expected value of the contest prize and thus lessen the severity of the conflict at home. However, unless the marginal return from guarding against terrorism is not too large or diminishes at a sufficiently fast rate, such a shock could imply, in equilibrium, both a greater sense of security among the groups against external threats and a greater conflict between them in the domestic struggle for power.
\end{abstract}

(C) 2004 Elsevier B.V. All rights reserved.

JEL classification: D72; D74; H56

Keywords: Terrorism; Rent-seeking; Resource allocation

\section{Introduction}

In the past, wartime crises have typically sparked an increased awareness by Americans of their common national identity and a desire to work together on local and national fronts in response. ${ }^{1}$ Thus, from a historical perspective, the effect of terrorist attacks to evoke solidarity and patriotism, such as that observed in the United States following the events of

* Tel.: +1-949-824-3190; fax: +1-949-824-2182.

E-mail address: mrgarfin@uci.edu (M.R. Garfinkel).

1 See, in particular, Skocpol (2002) who draws on qualitative evidence in making the relevant comparisons. She argues further, however, that sudden changes in civic attitudes today are not likely translate into increased civic participation as they had in the distant past, unless the government engages in mass mobilization, since there are relatively few civic institutions currently in place through which any newfound energies can be channelled. 
September 11th 2001, would not appear to be especially unusual. ${ }^{2}$ But what can economics tell us about the relation between increased threats to national security and domestic politics? Does the outbreak of war necessarily weaken domestic conflict?

The analysis of this paper aims to address these and related issues, building on a simple, one-nation model of domestic politics. Specifically, in the spirit of the emerging literature on conflict and appropriation, the analysis envisions groups within a single nation as competing in a contest in the current period for power to redistribute future income in their favor. ${ }^{3}$ An additional layer of conflict - namely, global terrorism-motivates their collective action. ${ }^{4}$ While each group struggles to secure a share of future income for itself, together they can guard against terrorism to protect the income available for everyone in the future. ${ }^{5}$

The analysis highlights the effect of an increased threat of terrorism on the groups' overall sense of security and, thus, their expected payoffs from participating in the domestic contest; this effect, in turn, influences the groups' current production, guarding and contest activities. A terrorist attack, if successful, destroys a fixed fraction of the nation's future income. Otherwise, the nation's future income is left intact. An increased threat-i.e., either a greater likelihood of a successful terrorist attack or a greater fraction of income destroyed in the event of a successful attack - given the groups' guarding choices, tends to reduce their overall sense of security, inducing them to discount the contest prize of power by more.

But the groups' guarding decisions are likely to change too. Unless the increased threat of terrorism undermines the marginal effectiveness of guarding, the incentive to guard necessarily increases. Such a response would tend to offset the direct effect of the increased threat on their sense of security. Thus, whether the degree of domestic conflict is amplified or dampened depends on the groups' collective resolve to restore their overall sense of security.

In the context of the model of this paper, provided that the marginal return from guarding is not too large or diminishes at a sufficiently fast rate, the equilibrium sense of security would remain lower. The analysis predicts in this case, consistent with the apparent shift in U.S. voters' attitudes as was documented by the news media in much of the year following the September 11 terrorist attacks, a weakening of the degree of

\footnotetext{
2 As many Americans reached out to help those in need through charitable contributions of their money and time, Democrats and Republicans in Congress alike joined forces with President George W. Bush to wage war against the terrorists in Afghanistan. See, for example, "Getting to grips with evil" The Economist, September 22, 2001, pp. 28-29.

3 This literature, which abandons the traditional paradigm that treats the existence and costless enforcement of property rights as given, can be traced back to the pioneering work of Haavelmo (1954, pp. 91-98). More recent contributions include Hirshleifer (1991, 1995), Skaperdas (1992) and Grossman and Kim (1995). See Garfinkel and Skaperdas (2000) who provide a brief overview.

4 "Terrorism" in this paper could be interpreted more broadly as an act of war launched against the nation. In any case, it is treated here as exogenous. See Sandler and Enders (2004) who survey the small but growing theoretical and empirical literature on the economics of terrorism.

5 In considering two layers of conflict of this sort, the present analysis is related to the literature on collective rent-seeking. See Nitzan (1994) for an excellent survey. But, in contrast, there is no presumption here that binding commitments (e.g., sharing rules) among the groups within the nation are possible.
} 
conflict within the nation. ${ }^{6}$ The predicted effect on current income, however, is ambiguous.

Moreover, the increased threat need not weaken the degree of conflict at home. If the marginal return from guarding is too large or does not diminish at a sufficiently fast rate, an increased threat of terrorism could induce a large enough increase in protection to induce groups to increase their valuation of the contest prize. That is to say, the increased external threat could imply, in equilibrium, both a greater sense of security among the groups within this nation against future acts of terrorism and a greater degree of conflict between them. In this case, current income necessarily falls. These findings suggest perhaps that, as America continues its fierce battle against terrorism and the heightened sense of vulnerability dissipates, "politics as usual" will make a much stronger comeback.

In what follows, the next section presents the analytical framework: a model of domestic conflict, which is essentially a rent-seeking model modified to allow for exogenous shocks that reduce the total amount of rents to be divided and, at the same time, for the allocation of resources by groups to reduce the likelihood that such shocks occur. ${ }^{7}$ Section 3 characterizes the solutions for each group's participation in the domestic conflict and their incentives to guard against terrorist attacks. Given that characterization, Section 4 identifies the conditions under which domestic conflict would be expected to become more or less severe with an increased external threat of terrorism and examines the corresponding implications for output. Section 5 concludes.

\section{Analytical framework}

Consider a two-period economy in which a single consumption good is produced. Normalizing its price at unity, the consumption good is taken as the numeraire. The economy is populated by $n+1$ risk-neutral groups, each of size 1 , having identical preferences defined over current and expected future consumption. ${ }^{8}$ The groups, indexed by $k$, compete in a nonviolent way for power. The benefit of being in the position of power is to be able to extract resources from all others. In particular, the one group in power in period $t, t=1,2$, receives a transfer of resources through the "taxation" of the other $n$

\footnotetext{
${ }^{6}$ In the weeks immediately following the attacks, domestic dissent was nowhere to be found in the political arena. Although partisan divisions on issues other than terror remained strongly in place throughout the year following the attacks, voters' heightened sense of vulnerability to terrorism and their relatively high approval ratings of President George W. Bush appeared to make Democrats and even Republicans reluctant to challenge the President on any issue. See for example, Herbert, Rob, “As Bush's stature rises..." The New York Times, January 31, 2002), p. 25; Balz, Dan and Broder, David S. “On Issues Except War, Voters Still Disengaged; Politics' Value Wants for Many After Sept. 11" The Washington Post, February 24, 2002, p. 1; and Brownstein, Ronald. "The Nation; A Year After; Attacks Produced a Seismic Shift in the Political Agenda" The Los Angeles Times, September 3, 2002, p. 1.

7 The model could be applied to analyze a variety of shocks, other than those arising from terrorist activitye.g., floods, nuclear power accidents, and global warming.

8 Since the analysis abstracts from issues of collective action at this level, groups could be thought of alternatively as individuals. The qualitative results derived below would follow even if we were to allow for the strategic interaction that naturally arises within groups as well as that which arises between groups (thereby adding a third layer of conflict) but at a considerable notational and computational expense.
} 
groups in that period. ${ }^{9}$ The identity of the first-period group in power is exogenously given. Thus, the analysis considers only that domestic conflict which emerges towards the end of the first period, resulting possibly in a transfer of power between the first and second periods. To fix ideas, suppose that the first $n$ groups, $k \in \mathrm{O}=\{1,2, \ldots, n\}$ are those who are not in power in $t=1$. The $n+1$ th group is the group in power in period $t=1$ and is indicated by $k=I$.

In the first period, whether in or out of power, each group has one unit of time to allocate among three different activities: earning income, contesting political power for the second period, and guarding against terrorist activity. Possibly having a direct impact on second-period consumption by all groups as described in more detail below, terrorist activity reflects the second layer of conflict in this framework. Suppose that a group $k$, allocates $e_{k}$ units of effort towards the struggle for political power and $g_{k}$ units of effort towards guarding against external threats. Then that group's earned income is $w\left(1-e_{k}-g_{k}\right)$, where $w$ denotes the wage rate. Assume that $w$ is exogenously given and fixed. ${ }^{10}$

Actual consumption by each group in the first period will differ from that group's earned income due to the redistribution of goods as the group initially in power, $k=I$, collects a lump sum tax from the other $n$ groups. Let $\tau$ denote this tax, which is given exogenously. ${ }^{11}$ Then, first-period consumption by each group not in power initially, $k \in \mathrm{O}$, is $w\left(1-e_{k}-g_{k}\right)-\tau$; and consumption by the incumbent group $k=I$ is $w\left(1-e_{I}-g_{I}\right)+n \tau$.

The analysis assumes that the outcome of the domestic struggle for power in the second period depends on the efforts put forth by each of the groups $\left\{e_{k}\right\}_{k}$. In particular, the probability that group $k$ wins the contest is

$$
\pi_{k}= \begin{cases}e_{k} / E & \text { if } k \in \mathcal{O} \\ \lambda e_{k} / E & \text { if } k=I\end{cases}
$$

where $E=\sum_{k \in \mathcal{O}} e_{k}+\lambda e_{I}$ and $\lambda \geq 1$,

when $E>0$; otherwise, $\pi_{k}=1 /(n+1)$ for all $k$. This specification of the contest success function, first introduced by Tullock (1980), admits the possibility that the group in power

9 Focussed on a somewhat refined form of conflict within the nation, the basic model has a flavor much like those in the rent-seeking literature-e.g., Hillman and Riley (1989). In a related analysis of domestic politics, Garfinkel (1994) assumes that preferences defined over the composition of peaceful production (private versus public consumption goods) vary across individuals within the nation. But with equal (lump sum) taxation, the conflict reflected in this variation similarly results in a redistribution of resources.

10 Since wages are independent of $k$, one might think of the groups as forming along ethnic lines, though their objectives are purely economic. See Robinson (2001) for a very interesting analysis of class and ethnic conflict. Groups divide along ethnic lines; but within-group variation in income may, in turn, translate into inequality of income across groups. In this setting, Robinson finds that ethnic differences might result in more conflict than differences in classes alone even when there is social mobility.

11 The analysis assumes a lump sum tax only for convenience. Assuming instead a distortionary tax does not change the qualitative results, but does make the analysis considerably less revealing. 
in period $t=1$ has an advantage relative to the other groups: $\lambda>1 .^{12}$ That is, the incumbent group's efforts are naturally more effective at the margin in manipulating the system to secure political support. ${ }^{13}$

Since individuals live only two periods, there are no choices to be made in the second period, $t=2 .{ }^{14}$ Each group earns $w$, implying an aggregate output of $(n+1) w$. As in the first period, however, this income will be redistributed through the taxation. Specifically, the group in power in the second period collects $\tau$ from each of the other $n$ groups, giving that group an after-tax income of $V_{I} \equiv w+n \tau$ while leaving each of the other groups with an after-tax income of $V_{O} \equiv w-\tau$. Thus, the expected after-tax income for any group $k$ is the weighted sum, $\pi_{k} V_{I}+\left(1-\pi_{k}\right) V_{O}$ or equivalently $w-\tau+\pi_{k}(n+1) \tau$.

But, the acts of terrorism launched against this economy imply that $V_{I}$ and $V_{O}$ represent only potential payoffs. Likewise, the difference between these potential payoffs, $V_{I}-V_{O}=(n+1) \tau$, represents at most the potential prize of the contest for power. It is realized by the winner in period $t=2$ only in the event that all attempted acts of terrorism are thwarted, an event which occurs with probability $\theta$. Thus, the weighted sum, $\pi_{k} V_{I}+\left(1-\pi_{k}\right) V_{O}$, represents the expected payoff, conditional on the terrorists' failure. In the event that an act of terrorism is successfully launched against this economy, which occurs with probability $1-\theta$, a fixed fraction of all income is destroyed. Let this fraction be denoted by $\rho \in(0,1]$. In this event, the payoff to the group that holds power in period $t=2$ is $(1-\rho) V_{I}$, and that to all others is $(1-\rho) V_{O}$, implying a smaller prize to the winner of the contest for power: $(1-\rho)\left[V_{I}-V_{O}\right]$. And, the expected second-period payoff for any group $k$, conditional on a successful attack, is only $(1-\rho)\left[\pi_{k} V_{I}+\left(1-\pi_{k}\right) V_{O}\right]$.

Assume that the probability of avoiding such destruction, given the extent of terrorist activity which is denoted by $X>0$, is strictly increasing in the total time allocated to guarding by all groups in the initial period $t=1, G \equiv \Sigma_{k} g_{k}$, but at a diminishing rate:

$$
\theta(G, X) \in[0,1)
$$

for $G \geq 0$, where $\partial \theta(G, X) / \partial G \equiv \theta_{G}>0, \quad \partial^{2} \theta(G, X) / \partial G^{2} \equiv \theta_{G G}<0$, and $\partial \theta(G, X) / \partial X \equiv \theta_{X}$ $<0 .{ }^{15}$ Note that this specification does not preclude the possibility that, without protective measures taken against terrorism in period $t=1(G=0)$, the terrorists' attacks might be

12 See Hirshleifer (1989) who discusses the properties of this specification (without an advantage for the incumbent group) and a related one.

13 For example, the group in power might be able to make use of state controlled resources (e.g., the army and police) to prevent others from voicing any opposition. At the same time, the incumbent group might have at its disposal the use of a state-owned broadcasting system to communicate its mission to others. See Konrad (2002) for an interesting analysis that considers both this and a "head-start" advantage for the incumbent in the struggle for power.

14 Accordingly, there is no need to introduce additional notation whereby the group in power in period $t=2$ can be distinguished from all others.

15 One might suppose that the group in power in the initial period is relatively more effective in guarding against terrorism. In a more fully articulated model, this comparative advantage might reflect increasing returns to scale in the technology of defense enjoyed by the state. Or, as suggested by Grossman (2002), it could reflect the state's ability to "enforce a collective choice." As will become obvious below, in this model with lump sum taxes, the incumbent has a greater incentive to contribute to guarding even without any such advantage. 
entirely undermined with a strictly positive probability; however, eliminating the possibility of terrorist success (ex ante) is not feasible.

\section{Equilibrium analysis}

In the first period, each group $k$ chooses a labor allocation $\left\{e_{k}, g_{k}\right\}$ so as to maximize the expected present discounted sum of its consumption over the two periods, $U_{k}$ :

$$
U_{k}=w\left(1-e_{k}-g_{k}\right)-\left(1-s_{k}\right) \tau+s_{k} n \tau+\beta \Theta(G, X, \rho)\left[w-\tau+\pi_{k}(n+1) \tau\right],
$$

where

$$
s_{k}= \begin{cases}0 & \text { if } k \in \mathcal{O} \\ 1 & \text { if } k=I\end{cases}
$$

$\beta \in(0,1]$ denotes the common discount factor; reflecting the groups' common sense of security against terrorism, $\Theta(G, X, \rho)$ is given by

$$
\Theta(G, X, \rho) \equiv \theta(G, X)+[1-\theta(G, X)](1-\rho)=1-\rho[1-\theta(G, X)]<1 ;
$$

and, as previously defined, $G \equiv \Sigma_{k} g_{k}$. The groups' optimizing choices are made independently, subject to contest success function (1) and the guarding technology (2) and given the external threat of terrorism, $X$. Suppose further, as implicitly assumed here, that the inequality constraint, $1-e_{k}-g_{k} \geq 0$, is not binding for any group $k$.

\subsection{Participation in the domestic conflict}

Consider first each group's optimal choice of effort allocated to the contest for power, $e_{k}$, given its choice of guarding, $g_{k}$, and the choices made by all other groups, $\left\{e_{j}, g_{j}\right\}_{j \neq k}$. The payoff maximizing effort levels allocated to this contest, $e_{k}$, satisfy the following conditions:

$$
\begin{aligned}
& \beta \Theta(G, X, \rho) \frac{E-e_{k}}{E^{2}} R-1 \leq 0 \quad \text { for } k \in \mathcal{O} \\
& \lambda \beta \Theta(G, X, \rho) \frac{E-\lambda e_{I}}{E^{2}} R-1 \leq 0 \quad \text { for } k=I
\end{aligned}
$$

where $R \equiv\left[V_{I}-V_{O}\right] / w=(n+1) \tau / w$ denotes the potential prize from the domestic contest normalized by the (constant) marginal opportunity cost of participating in that contest $(w)$. For each group not initially in power, $k \in \mathcal{O}$, the first condition is met as a strict equality when $e_{k}>0$. Similarly, the second condition is satisfied as a strict equality when $e_{I}>0$. Focusing on the quasi-symmetric solution where $e_{k}=e_{O}$ for all $k \in \mathcal{O}, E=n e_{O}+\lambda e_{I}$. 
Provided $\Theta(G, X, \rho)>0$ given $G \geq 0$ and $X>0$, the conflict technology as specified in Eq. (1) implies that $E>0$ in equilibrium. ${ }^{16}$ Combining Eq. (5a) for $k \in \mathrm{O}$ and Eq. (5b) as strict equalities yields the following solutions:

$$
\begin{aligned}
& e_{O}^{*}=\frac{\beta \Theta(G, X, \rho) \lambda n R}{(1+\lambda n)^{2}} \\
& e_{I}^{*}=\frac{\beta \Theta(G, X, \rho) n R}{(1+\lambda n)^{2}}[1+(\lambda-1) n] \\
& E^{*}=n e_{O}^{*}+\lambda e_{I}^{*}=\frac{\beta \Theta(G, X, \rho) \lambda n R}{1+\lambda n},
\end{aligned}
$$

with $\Theta(G, X, \rho)$ as defined in Eq. (4) given $G$ and $X$. As revealed by a close inspection of these solutions, if either $n=1$ so that there are only two groups in total or $\lambda=1$ so that there is no incumbency advantage, all groups allocate the same effort to the contest for power: $e_{O}^{*}=e_{I}^{*}$. But, only if $\lambda=1$, will all groups have an equal chance of success in that contest. If neither of these conditions is satisfied $(n>1$ and $\lambda>1)$, then those groups not in power will devote more labor resources to the domestic conflict than the incumbent group: $e_{O}^{*}>e_{I}^{*}$.

When evaluated at $\left\langle e_{O}^{*}, e_{I}^{*}\right\rangle$ given $G$ as well as $X$, Eq. (1) for $k=I$ equals the equilibrium degree of political stability, $\pi_{I}^{*}$-i.e., the probability that the one group holding power in the first period $k=I$ will continue to hold power in the second:

$$
\pi_{I}^{*} \equiv \frac{\lambda e_{I}^{*}}{\lambda e_{I}^{*}+n e_{O}^{*}}=1-\frac{n}{1+\lambda n} .
$$

This probability is at least as large as the probability that another given group $k \in \mathrm{O}$ will seize the position of power, or

$$
\pi_{O}^{*} \equiv \frac{e_{O}^{*}}{\lambda e_{I}^{*}+n e_{O}^{*}}=\frac{1}{1+\lambda n},
$$

since $\lambda \geq 1$. Henceforth, the analysis assumes that the group initially in power has a strictly positive advantage in the domestic contest $(\lambda>1)$, implying that $\pi_{I}^{*}>1 /(n+1)>\pi_{O}^{*}$, even though $e_{I}^{*} \leq e_{O}^{*}$.

In addition, from Eq. (7), one can see that the equilibrium degree of political stability, $\pi_{I}^{*}$, is decreasing in the number of groups in $\mathcal{O}, n$, and is increasing in the incumbent group's advantage, $\lambda \geq 1$, but is independent of the normalized potential prize, $R$. Furthermore, the equilibrium degree of political stability is independent of the external threat of terrorism, as reflected in $\Theta(G, X, \rho)$. Regardless of its effect on the equilibrium

\footnotetext{
16 Otherwise, given $e_{j}=0$ for $j \neq k$, any group $k$ could secure a victory in the contest with an infinitesimally small amount of effort. Since no rational, forward-looking group would leave such an opportunity unexploited, $e_{k}=0$ for $k=1,2, \ldots, n+1$ cannot be an equilibrium outcome.
} 
allocation of resources to protect the economy $G$, terrorism influences each group's labor allocation to the domestic conflict proportionately so as to leave the equilibrium degree of political stability, $\pi_{I}^{*}$, unchanged. ${ }^{17}$

\subsection{Equilibrium guarding against terrorist attacks}

To proceed, now consider the groups' labor allocation to guarding. Each group's choice maximizes its expected payoff Eq. (3) subject to Eqs. (1) and (2) with Eq. (4), given $X$ and the equilibrium winning probabilities $\pi_{I}^{*}$ and $\pi_{O}^{*}$. The first-order condition to this maximization problem for each group $k$ implies

$$
\Gamma_{k}(G) \equiv \beta \rho \theta_{G}(G, X)\left[1+R\left[\pi_{k}^{*}-\frac{1}{1+n}\right]\right]-1 \leq 0
$$

for $k=1, \ldots, n+1$, where as previously defined $G \equiv \Sigma_{k} g_{k}$ and $R \equiv(n+1) \tau / w$; for $k=I, \pi_{k}^{*}$ is given by Eq. (7); and for $k \in \mathcal{O}, \pi_{k}^{*}$ is given by Eq. (8). For each group $k$, the condition in Eq. (9) is satisfied as a strict equality when $\Gamma_{k}\left(G^{-k}\right)>0$, where $G^{-k} \equiv \sum_{j \neq k} g_{j}$ given $g_{j} j \neq k$, so that $g_{k}^{*}>0$. Whether satisfied as a strict equality or inequality, these conditions show that groups $k \in \mathcal{O}$ will choose the same guarding allocation. Let that optimizing allocation be indicated by $g_{O}^{*}$. Thus, $G=n g_{O}^{*}+g_{I}$.

But, under the maintained assumption that the incumbent group has a relative advantage in the contest for power $(\lambda>1)$, the $n+1$ conditions in Eq. (9) cannot all be satisfied as strict equalities. Thus, an interior solution for all $g_{k}$ is not possible. In fact, since $\pi_{I}^{*}>\pi_{O}^{*}, G^{*}>0$ holds if and only if $g_{I}^{*}>0 .{ }^{18}$ Specifically, we have

$$
g_{O}^{*}=0 \text { and } G^{*}=g_{I}^{*}\left\{\begin{array}{l}
= \\
>
\end{array}\right\} 0 \text { if } \Gamma_{I}(0)\left\{\begin{array}{l}
\leq \\
>
\end{array}\right\} 0 .
$$

When the marginal return from guarding $\left(\theta_{G}\right)$, the discount factor $(\beta)$ and/or the potential damage from terrorist attacks $(\rho)$ are relatively small so that $\Gamma_{I}(0) \leq 0$, no resources are allocated to guarding in equilibrium: $g_{I}=G^{*}=0$. But, when $\Gamma_{I}(0)>0$, the equilibrium value of aggregate guarding is implicitly defined by Eq. (9) for $k=I$ as a strict equality. Thus, we can write $G^{*}=g_{I}^{*}=g_{I}^{*}\left(X, \rho, \pi_{I}^{*}\right) .{ }^{19}$

Then, from Eq. (6a)-(6c) the equilibrium allotment to the contest for power by groups $k \in \mathcal{O}$ can be written as a function of $X, \rho$ and $\pi_{I}^{*}$. Aggregating over the $n$

${ }^{17}$ Hence, political instability (or the frequency with which power changes hands) measured by $1-\pi_{I}^{*}$ need not be a good indicator of the severity of the domestic conflict or of its implications for resource allocation.

18 When taxes are distortionary, however, the incumbent group need not have a greater incentive to guard, since such a tax increases the relative opportunity cost of this group's time at the margin, which also raises the possibility that $\pi_{I}^{*}<\pi_{O}^{*}$ even when $\lambda>1$. Nevertheless, as suggested earlier, the qualitative nature of the central results derived below do not depend on whether taxes are lump sum or distortionary.

19 Note that, consistent with Garfinkel (1994), an increase in the degree of political stability $\pi_{I}^{*}$, caused by exogenous increase in the incumbency advantage $\lambda$, would induce more guarding $G^{*}$ against external threats. 
groups, we have $n e_{O}^{*}=n e_{O}^{*}\left(X, \rho, \pi_{I}^{*}\right)$. Similarly, we can write the incumbent group's equilibrium allotment to the contest for power as $e_{I}^{*}=e_{I}^{*}\left(X, \rho, \pi_{I}^{*}\right)$. The total allocation to production by all groups is simply the residual: $n+1-n e_{O}^{*}-e_{I}^{*}-g_{I}^{*}$, which is strictly positive under the maintained assumption that the inequality constraint, $1-e_{k}-g_{k} \geq 0$, is not binding for any group.

\section{Threats of terrorism and domestic conflict}

The analysis now turns to study the effects of global threats of terrorism on domestic conflict. Although threats of terrorism have no direct effect on the equilibrium degree of political stability $\pi_{I}^{*}$, the solutions shown in Eq. (6a)-(6c) reveal that they do influence the groups' incentive to participate in the domestic struggle for power through their effect on the groups' sense of security, $\Theta(G, X, \rho)$. Indeed, an increased threat of terrorism, such as that perceived following the September 11, 2001 attacks, could be represented by

- a positive shock to $\rho$, or an increase in the fraction of income destroyed in the event of a successful attack given $\theta(G, X)$, as the horrific events on that day shattered the belief that (transnational) terrorists could do relatively little harm within the borders of the United States; or

- a positive shock to $X$, or an increase in the likelihood of a successful terrorist attack $\theta(G, X)$ given $G$, as the events themselves and the information that quickly surfaced thereafter revealed a greater resolve, cohesion and overall strength of the terrorist organization than had been previously perceived by most.

Focusing on the total amount of labor allocated to the contest for power, or $F^{*} \equiv n e_{O}^{*}+e_{I}^{*}$, as the relevant measure of the severity of the conflict at home, ${ }^{20}$ the potential influence of such shocks is formally represented as

$$
\begin{aligned}
& \frac{d F^{*}}{d \rho}=\frac{\beta n R}{1+\lambda n}\left[1+\frac{n(\lambda-1)}{1+\lambda n}\right] \frac{d \Theta\left(G^{*}, X, \rho\right)}{d \rho} \\
& \frac{d F^{*}}{d X}=\frac{\beta n R}{1+\lambda n}\left[1+\frac{n(\lambda-1)}{1+\lambda n}\right] \frac{d \Theta\left(G^{*}, X, \rho\right)}{d X} .
\end{aligned}
$$

Hence, to identify the effects of an increased threat of terrorism on the severity of conflict at home, we need only evaluate the sign of the derivatives $d \Theta\left(G^{*}, X\right) / d \rho$ and $d \Theta\left(G^{*}, X\right) / d X$.

\footnotetext{
20 As one can easily verify, $F=E+(1-\lambda) e_{I}$. Since, by assumption, $\lambda>1, F<E$. Nonetheless, the signs of $d F^{*} / d \rho$ and $d F^{*} / d X$ are identical respectively to those of $d E^{*} / d \rho$ and $d E^{*} / d X$.
} 
From Eq. (4), given the amount of guarding $G$, either sort of shock would reduce the sense of security among the groups against terrorism $(\Theta)$ and, thus, would imply more discounting of the future prize from the domestic contest for power:

$$
\begin{aligned}
& \left.\frac{\partial \Theta\left(G^{*}, X, \rho\right)}{\partial \rho}\right|_{d G=0}=-\left[1-\theta\left(G^{*}, X\right)\right]<0 \\
& \left.\frac{\partial \Theta\left(G^{*}, X, \rho\right)}{\partial X}\right|_{d G=0}=\rho \theta_{X}<0 .
\end{aligned}
$$

Of course, any perceived change in the threat of terrorism would be expected to influence the groups' incentive to guard. Factoring in these indirect effects, we have

$$
\begin{aligned}
& \frac{d \Theta\left(G^{*}, X, \rho\right)}{d \rho}=-\left[1-\theta\left(G^{*}, X,\right)\right]+\rho \theta_{G} \frac{d G^{*}}{d \rho} \\
& \frac{d \Theta\left(G^{*}, X, \rho\right)}{d X}=\rho\left[\theta_{X}+\theta_{G} \frac{d G^{*}}{d X}\right] .
\end{aligned}
$$

The two subsections that follow analyze the implications of shocks to $\rho$ and $X$, in turn, considering both the indirect and direct effects and identifying the conditions under which shocks to each would lessen the severity of conflict at home. ${ }^{21}$

\subsection{When the potential destruction from terrorism increases}

Consider first the effect of an increase in the fraction of income destroyed in the event of a successful terrorist attack, $\rho$. Suppose initially that $g_{I}^{*}=G^{*}>0$. Then, applying the implicit function theorem to Eq. (9) for $k=I$ with Eq. (2), the second-order condition and the envelope condition shows

$$
\frac{d G^{*}}{d \rho}=-\frac{\theta_{G}}{\theta_{G G} \rho}>0 .
$$

Since the marginal return to guarding is diminishing $\left(\theta_{G G}<0\right)$ by assumption, the sign of this expression is determined by the sign of the numerator, the marginal effect of guarding on the likelihood of thwarting all terrorist attacks - which is positive. An exogenous increase in the potential damage caused by a successful terrorist attack (as measured by $\rho$ )

\footnotetext{
21 An appendix provides details under two particular specifications for the guarding technology $\theta(G, X)$,
} which are discussed briefly in the main text. 
induces an increase in guarding, which tends to offset the direct effect of the shock on $\Theta(G, X, \rho)$. Combining Eqs. (13) and (12a) gives the full effect:

$$
\frac{d \Theta\left(G^{*}, X, \rho\right)}{d \rho}=-\left[\left[1-\theta\left(G^{*}, X\right)\right]+\frac{\theta_{G}^{2}}{\theta_{G G}}\right] .
$$

With Eq. (11a), this expression implies

Proposition 1. An exogenous increase in the income destroyed in the event of a successful terrorist attack $(\rho)$ reduces the severity of domestic conflict $\left(F^{*}\right)$ when $d \Theta\left(G^{*}, X, \rho\right) / d \rho<0$ which holds iff $1-\theta\left(G^{*}, X\right)>-\theta_{G}^{2} / \theta_{G G}$.

Although an exogenous increase in the potential harm caused by terrorism would induce more guarding, the condition for that shock to reduce the severity of conflict at home, as stated in the proposition, ensures that the increase in guarding is not so large as to cause the groups' sense of security, $\Theta$, to increase on net. This condition is simply that the marginal return from guarding is not too large or that it diminishes at a sufficiently fast rate.

If, for example, $\theta(G, X)=G /(G+X)$, an increase in the potential damage caused by terrorism $\rho$ would induce increased protection against external threats, but necessarily would result in more discounting of the prize from the contest for power. While the degree of domestic stability, $\pi_{I}^{*}$, would be unaffected, the intensity of domestic conflict as measured by $F^{*}$ would fall as a result. Alternatively, if $\theta(G, X)=G^{\alpha} /(1+X)$ where $\alpha \in(0,1)$, an increase in the potential damage caused by terrorism would amplify the conflict between groups, unless $\alpha$ were sufficiently small. ${ }^{22}$

Note that, when the condition stated in Proposition 1 is satisfied, the implications for output are generally ambiguous. The amount of labor allocated to the domestic conflict falls, while that allocated to guarding rises. However, when that condition is not satisfied, the effect on output is clear. Specifically, since the amount of labor devoted to both the domestic contest for power and guarding rises, the remaining allotment for production necessarily falls.

\subsection{When the likelihood of a successful terrorist attack increases}

Now consider the effect of an exogenous increase in the likelihood of a successful terrorist attack, as measured by an increase in $X$. Assuming initially that $g_{I}^{*}>0$, an application of the implicit function theorem to Eq. (9) for $k=I$ with Eq. (2) shows

$$
\frac{d G^{*}}{d X}=-\frac{\theta_{G X}}{\theta_{G G}} \gtreqless 0 \quad \text { if } \theta_{G X} \gtreqless 0 .
$$

Since $\theta_{G G}<0$, Eq. (15) reveals that the sign of the effect of an exogenous increase in the external threat (as measured by $X$ ) equals the sign of $\theta_{G X}$, which could be positive or negative. In the case that an increase in the external threat decreases the marginal return from guarding $\left(\theta_{G X}<0\right)$, the shock induces less self-protection. In this case, the indirect and

\footnotetext{
22 In particular, $\alpha<1-\theta\left(G^{*}, X\right)$ must hold. See Appendix A for details.
} 
direct effects of such a shock on $\Theta(G, X)$ would reinforce each other. Otherwise, the indirect effect would tend to offset the direct effect.

Combining Eqs. (15) and (12b) shows

$$
\frac{d \Theta\left(G^{*}, X, \rho\right)}{d X}=\rho\left[\theta_{X}-\theta_{G} \frac{\theta_{G X}}{\theta_{G G}}\right] .
$$

With Eq. (11b), this expression, in turn, implies

Proposition 2. An exogenous increase in the likelihood of a successful terrorist attack $(X)$ reduces the severity of the conflict between groups $\left(F^{*}\right)$ when $d \Theta\left(G^{*}, X, \rho\right) / d X<0$, which holds if either (i) $\theta_{G X}<0$ or (ii) $\theta_{G X}>0$ and $\theta_{X}<\theta_{G} \theta_{G X} / \theta_{G G}$.

As stated in this proposition, a positive shock to the likelihood of success of terrorist activity could lower the incentive to guard $\left(\theta_{G X}<0\right)$, in which case the groups' sense of security, $\Theta$, would necessary fall, implying a negative effect on domestic conflict. In this case, the shock would induce a greater allocation of labor to production in period $t=1$. Even if the incentive to guard were to rise $\left(\theta_{G X}>0\right)$, the effect of the shock on domestic conflict would be negative provided again that the marginal return from guarding was not too large or diminished at a sufficiently fast rate. In this case, however, the effect on period $t=1$ production would be ambiguous.

Returning to the examples introduced above, if $\theta(G, X)=G /(G+X)$, an increase in $X$ could induce more or less guarding, depending on whether initially $G$ was less than or greater than $X$. By contrast, if $\theta(G, X)=G^{\alpha} /(1+X)$, the effect on guarding would unambiguously be negative. But, under either specification, the effect on the groups' overall sense of security would be the same-that is, negative. ${ }^{23}$ Hence, for both specifications, the effect of the increased threat of terrorism would be to reduce the severity of the conflict at home.

\section{Concluding remarks}

This paper has examined some of the implications of an increased threat of global terrorism on domestic politics, highlighting the direct and indirect effects of such threats on the nation's overall sense of security and thus the expected payoffs from participation in a domestic contest for power. That is, an increased threat of terrorism can reduce the gains that special interest groups would expect from rent-seeking activities, and so weaken their incentive to engage in this sort of activity, resulting in less internal conflict. But, even in the context of the simple model presented here where the only source of conflict concerns the distribution of income, the finding that domestic conflict becomes less severe with an increased threat of terrorism requires that the marginal return from guarding not be too large or that it diminish at a sufficiently fast rate. Unless this condition holds, one might reasonably predict the launching of a more extensive campaign against terrorism to increase the sense of security enjoyed by the groups in the economy. While detracting

\footnotetext{
23 Again, see Appendix A for details.
} 
from current production, the increased threat would amplify the struggle for power at home.

\section{Acknowledgements}

This paper was prepared for the DIW Berlin Workshop on the Economic Consequences of Global Terrorism June 2002. I am grateful to Stergios Skaperdas, the editors of this special issue, Tilman Brück and Bengt-Arne Wickström, and two anonymous referees for their helpful suggestions.

\section{Appendix A}

This appendix provides some details concerning the effects of terrorism $(\rho, X)$ on $\Theta\left(G^{*}, X\right)=1-\rho\left[1-\theta\left(G^{*}, X\right)\right]$ based on two specifications for $\theta(G, X)$ mentioned in Section 4.

Example 1. Suppose $\theta(G, X)=\mathrm{G} /(G+X)$ where $G \equiv \Sigma_{k} g_{k}$. Using Eq. (9) with Eq. (10) given $X$, one can find the following solution for guarding:

$$
\begin{aligned}
& G^{*}=g_{I}^{*}= \begin{cases}0 & \text { if } \sqrt{z_{1}}<X \\
\sqrt{z_{1}}-X & \text { otherwise }\end{cases} \\
& z_{1} \equiv \rho \beta X\left[1+R\left[\pi_{I}^{*}-\frac{1}{n+1}\right]\right] .
\end{aligned}
$$

In turn, this solution (when $G^{*}=g_{I}^{*}>0$ ) implies $\theta\left(G^{*}, X\right)=\left(\sqrt{z_{1}}-X\right) / \sqrt{z_{1}}$. Furthermore, one can easily see, using Eq. (13) or simply by differentiating Eq. (A.1a,b), that $d G / d \rho=\frac{1}{2} \sqrt{z_{1}} / \rho>0$. In addition, we have $\theta_{G}\left(G^{*}, X\right)=X / z_{1}$. These findings together with Eq. (12a) yield $d \Theta\left(G^{*}, X\right) / d \rho=-(1 / 2)\left[1-\theta\left(G^{*}, X\right)\right]<0$. From either Eq. (A.1a,b) or Eq. (15), one can also verify that $d G / d X=\left[\frac{1}{2} \sqrt{z_{1}}-X\right] / X$ which could be positive or negative and $\theta_{X}\left(G^{*}, X\right)=-\left[\sqrt{z_{1}}-X\right] / z_{1}<0$. Then, using Eq. (12b) yields $d \Theta\left(G^{*}, X\right) /$ $d X=-(1 / 2) \rho\left[1-\theta\left(G^{*}, X\right)\right] / X<0$.

Example 2. Suppose $\theta(G, X)=G^{\alpha} /(1+X)$ where $G \equiv \Sigma_{k} g_{k}$. Then, from Eqs. (9) and (10) given $X$, one can find the following solution for guarding:

$$
\begin{aligned}
& G^{*}=g_{I}^{*}=z_{2}^{\frac{1}{1-\alpha}} \\
& z_{2} \equiv \rho \beta\left[1+R\left[\pi_{I}^{*}-\frac{1}{n+1}\right]\right] /[1+X] .
\end{aligned}
$$

For this example, maintaining the assumption that the inequality constraint for $k=I$,

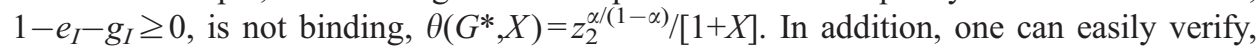


using Eq. (A.2a,b) or Eq. (13), that $d G / d \rho=z_{2}^{1 /(1-\alpha)} /[\rho(1-\alpha)]>0$ and $\theta_{G}\left(G^{*}, X\right)=\alpha /$ $\left[(1+X) z_{2}\right]$. In turn, these findings with Eq. (12a) imply $\left.d \Theta\left(G^{*}, X\right) / d \rho=-1+\theta\left(G^{*}, X\right)\right] /$ $[1-\alpha]$ which is negative if and only if $\alpha<1-\theta\left(G^{*}, X\right)$. From Eq. (A.2a,b) or Eq. (15), one can also find $d G / d X=-z_{2}^{1 /(1-\alpha)} /[(1-\alpha)(1+X)]<0$ and $\theta_{X}\left(G^{*}, X\right)=-\theta\left(G^{*}, X\right) /[1+X]<0$. With Eq. (12b), these results imply $d \Theta\left(G^{*}, X\right) / d X=-\rho \theta\left(G^{*}, X\right) /[(1+X)(1-\alpha)]<0$.

\section{References}

Garfinkel, M.R., 1994. Domestic politics and international conflict. American Economic Review 84, 1292 - 1309. Garfinkel, M.R., Skaperdas, S., 2000. On the consequences of a broader view of self-interest in economics. American Economist 40, 5-16.

Grossman, H.I., 2002. "Make us a king": anarchy, predation, and the state. European Journal of Political Economy 18, 31-46.

Grossman, H.I., Kim, M., 1995. Swords or plowshares? A theory of the security of claims to property. Journal of Political Economy 103, 1275-1288.

Haavelmo, T., 1954. A Study in the Theory of Economic Evolution North-Holland, Amsterdam.

Hillman, A.L., Riley, J.G., 1989. Politically contestable rents and transfers. Economics and Politics 1, 17-39.

Hirshleifer, J., 1989. Conflict and rent-seeking success functions: ratio vs. difference models of relative success. Public Choice 63, 101-112.

Hirshleifer, J., 1991. The paradox of power. Economics and Politics 3, 177-200.

Hirshleifer, J., 1995. Anarchy and its breakdown. Journal of Political Economy 103, 26-52.

Konrad, K., 2002. Investment in the absence of property rights: the role of incumbency advantages. European Economic Review 46, 1521-1537.

Nitzan, S., 1994. Modelling rent seeking contests. European Journal of Political Economy 10, 41-60.

Robinson, J.A., 2001. Social identity, inequality, and conflict. Economics of Governance 2, 85-99.

Sandler, T., Enders, W., 2004. An economic perspective on transnational terrorism. European Economic Review, 20 (this issue).

Skaperdas, S., 1992. Cooperation, conflict and power in the absence of property rights. American Economic Review 82, 720-739.

Skocpol, T., 2002. Will 9/11 and the war on terror revitalize American civic democracy?. Political Science and Politics 35, 537-540.

Tullock, G., 1980. Efficient rent seeking. In: Buchanan, J.M., Tollison, R.D., Tullock, G. (Eds.), Toward a Theory of the Rent Seeking Society, pp. 3-15 Texas A\&M Univ. Press, College Station. 